\title{
O impacto do e-commerce na venda de bilhetes aéreos: a perspectiva de gestores de agências de viagem de Campo Grande, MS
}

\author{
The impact of e-commerce on the sale of air tickets: the perspective of \\ managers of travel agencies in Campo Grande, MS
}

\section{El impacto del e-commerce en la venta de billetes aéreos: la perspectiva de gestores de agencias de viajes de Campo Grande, MS}

\author{
Rodrigo Zampieri ${ }^{1}$ \\ Dores Cristina Grechi ${ }^{1}$
}

Recebido em 31/05/2018; revisado e aprovado em 19/12/2018; aceito em 23/12/2018

DOI: http://dx.doi.org/10.20435/inter.v20i3.2027

\begin{abstract}
Resumo: Neste trabalho buscou-se verificar o impacto da internet nas vendas de bilhetes aéreos das agências de viagem da cidade de Campo Grande, MS. A abordagem foi no sentido de identificar, sob o ponto de vista do gestor da agência, a influência da tecnologia no hábito dos consumidores. Como base de dados, utilizou-se o cadastro do Ministério do Turismo, o qual compreende pessoas físicas e jurídicas atuantes no setor de turismo no estado. A metodologia consistiu em pesquisa bibliográfica e de campo. Os resultados confirmam a teoria estudada no que se refere ao impacto da internet no comércio de passagens e no perfil dos novos consumidores. Palavras chave: comércio virtual; agência de viagem; internet; bilhetes aéreos.

Abstract: This work aimed to verify the impact of the internet on the air ticket sales of the travel agencies of the city of Campo Grande, MS. The approach was to identify, from the point of view of the agency manager, the influence of technology on consumer habits. The database was used as a register of the Ministry of Tourism, which includes individuals and legal entities active in the tourism sector in the state. The methodology consisted of bibliographical and field research. The results confirm the theory studied regarding the impact of the internet on ticket trading and the profile of new consumers.
\end{abstract}

Key words: virtual commerce; travel agency; internet; flight tickets.

Resumen: En este trabajo se buscó verificar el impacto de Internet en las ventas de billetes aéreos de las agencias de viajes de la ciudad de Campo Grande, MS. El enfoque fue para identificar, desde el punto de vista del gestor de la agencia, la influencia de la tecnología en el hábito de los consumidores. Como base de datos se utilizó el registro del Ministerio de Turismo, el cual comprende personas físicas y jurídicas actuantes en el sector de turismo en el estado. La metodología consistió en investigación bibliográfica y de campo. Los resultados confirman la teoría estudiada en lo que se refiere al impacto de Internet en el comercio de pasajes y en el perfil de los nuevos consumidores.

Palabras clave: comercio virtual; agencia de viajes; turismo; internet; boletos de avión.

\section{INTRODUÇÃO}

No início do século XX, quando começaram as primeiras viagens de avião, o acesso a esse meio de transporte era bastante restrito. Contudo a globalização, a popularização das facilidades, a segurança, o aumento da concorrência e a expansão da transmissão de dados através da internet foram aspectos que tiveram grande influência na democratização da aviação. Atualmente, de acordo com a Organização Internacional da Aviação Civil (ICAO), a aviação comercial tem capacidade de transportar cerca de 3,5 bilhões de pessoas por ano, ou seja, a metade da população mundial (VINHOLES, 2017).

No Brasil, com um território de dimensões continentais, o transporte aéreo não é apenas uma forma de locomoção, também aproxima cidades, é útil na área médica, na defesa da soberania do país, pulverização de plantações, resgates e salvamentos, acesso às áreas remotas, entre outros.

\footnotetext{
${ }^{1}$ Universidade de Mato Grosso do Sul (UEMS), Dourados, Mato Grosso do Sul, Brasil.
} 
No bojo do crescimento das viagens aéreas, surgiram outros negócios relacionados ao turismo, entre eles as agências de viagem. De acordo com a literatura (DIAS, 2005; COOPER et al., 2003), o pai do agenciamento turístico foi Thomas Cook, o qual organizou a primeira excursão para um grupo de fiéis que viajaram pelo interior da Inglaterra para participarem de um evento contra o alcoolismo.

As agências de viagens, como qualquer outro ramo do comércio, precisam de planejamento e da definição de um modelo de negócio para o sucesso do empreendimento. Esse modelo implica conhecimento de mercado, ou seja, como a empresa vai atuar e de que forma (MELLERDA-SILVA; MARCIANO, 2017).

Antes da explosão da internet, a compra de bilhetes aéreos só era possível através das lojas físicas das companhias aéreas ou poucas agências de turismo que detinham os sistemas necessários para esse fim. Após o crescimento substancial do uso da internet, o comércio eletrônico em geral foi se popularizando, e os bilhetes aéreos não foram exceção. Hoje é possível comprar uma passagem aérea para qualquer lugar do mundo, bastando ter um cartão de crédito nas mãos, um computador ou um smartphone conectado à internet. Consequentemente, a facilidade na compra de bilhetes aéreos trouxe, também, os riscos inerentes a esse tipo de comércio. Verificase que todos os setores na aviação utilizam essas facilidades, pois até as companhias aéreas que antes concentravam suas maiores vendas através de agências de viagens, passaram, também, a ser concorrentes, pois oferecem seus produtos em seus sites para o consumidor final sem a taxa de serviço cobrada pelas agências de viagem. Contudo ainda existem aqueles que continuam a comprar seus bilhetes através dos agentes de viagem. Sendo assim, o objetivo deste trabalho foi verificar se e como o comércio virtual tem afetado o comércio de bilhetes aéreos realizado por meio das agências físicas de Campo Grande- MS. Para alcançar o objetivo proposto, fez-se, além de revisão teórica sobre as tendências neste setor, pesquisa de campo entre os gestores das agências de viagens da cidade. Paralelamente ao objetivo principal, outros propósitos são apresentados, tais como: entender o cenário atual no que se refere ao uso da internet no comércio de produtos turísticos em geral; caracterizar o perfil do consumidor de produtos turísticos virtuais e físicos a partir das empresas investigadas e identificar aspectos positivos e negativos na relação das agências tradicionais de Campo Grande com o comércio virtual de bilhetes aéreos.

Campo Grande é a capital do Estado de Mato Grosso do Sul, tem 118 anos e, aproximadamente 874.000 habitantes (IBGE, 2017) ${ }^{2}$. Geograficamente está no centro do Estado, sendo a cidade com a maior malha aérea de Mato Grosso do Sul. Registrou-se 13.763 pousos e decolagens em Campo Grande, MS no ano de 2016 (INFRAERO, 2017)³. A oferta de agências físicas em Campo Grande, MS, compreende 146 empresas cadastradas (com a atividade de reserva e venda de passagens). Em contrapartida, tem-se quatro grandes OTAs (Online Travel Agencies) que atuam no Brasil, no segmento de bilhetes aéreos, sendo elas: Decolar; Expedia; Submarino Viagens e Viajanet (FONSECA, 2014). Trabalham, existem e são agências de viagem, só que com o âmbito de atuação muito maior do que as agências de Campo Grande, MS.

Observa-se que hoje a dependência da internet é muito grande, tanto para as OTAs, como para as agências físicas. Não é possível comprar um bilhete aéreo se não for através da internet (BRITO, 2017). Além disso, questões como o marketing agressivo das OTAs, o perfil dos novos

\footnotetext{
${ }^{2}$ Disponível em: https://cidades.ibge.gov.br/brasil/ms/campo-grande/panorama. Acesso em: 6 mar. 2017 , às $18 \mathrm{~h} 31$.

${ }^{3}$ Disponível em: www.infraero.gov.br/images/stories/Estatistica/anuario/anuario_2016.pdf. Acesso em: 8 set. 2017 , às $19 \mathrm{~h} 20$.
} 
consumidores, acordos operacionais exclusivos e o acesso facilitado de informações vêm transformando seriamente o ambiente de negócio das agências de viagens tradicionais.

Considerando todos os aspectos apresentados, este trabalho investigou essas mudanças usando como cenário a realidade de Campo Grande, MS. O artigo está organizado em introdução, revisão teórica, metodologia, resultados e discussão e considerações finais.

\section{A TECNOLOGIA DA INFORMAÇÃO E OS NOVOS PROCESSOS NAS EMPRESAS TURÍSTICAS}

O início da utilização da tecnologia da informação (TI) no turismo vem da década de 60 e evoluiu gradativamente com sistemas mais modernos que foram permitindo o acesso à informação de uma forma simplificada pelos clientes (BRITO, 2017, p. 68).

Nessa nova relação entre o consumidor e a agência de viagem, a internet tornou-se indispensável. Da década de 90 em diante, a dependência da internet foi sendo cada vez maior. O sistema de telefonia pela internet, chamado VOIP, reduziu de forma substancial o custo de telefonia, principalmente as ligações de longa distância.

A influência dos recursos de TI para o turismo é irreversível (BRITO, 2017), uma vez que há diminuição no uso de recursos humanos e a informação passa a ser difundida de forma instantânea. Diante desse cenário, é necessário um reposicionamento das agências de viagens físicas, que precisam ser consultoras, assessoras de viagens e não somente emissoras de bilhetes aéreos, pois as agências virtuais fazem esse serviço de forma mais cômoda para o cliente (OLIVEIRA; RESENDE, 2014). A segmentação da oferta e as demandas específicas são outros pontos que merecem ser destacados (ROLIM; ROLIM, 2016). Os funcionários e proprietários de agências de viagens físicas, necessitam inovar, buscar novos mercados, estar sensíveis a estas mudanças. A literatura e a observação do comportamento do mercado têm mostrado que a utilização dos recursos digitais, incluindo a internet, precisam ser explorados de forma que venham agregar ao segmento das agências de viagens, no atual cenário do turismo. O crescimento dos sites de compras de bilhetes aéreos online, deve-se também à ascensão das classes sociais $C$ e $D$, pois aumentou o poder de compra dessas classes, as quais viviam fora dessa realidade (MONTEIRO; MONTEIRO, 2014).

As OTAs investem milhões de dólares anualmente em publicidade (CEDEÑO, 2016) e faturaram no ano passado, no Brasil, a ordem de quase U\$367 milhões (OTTO, 2016), vendendo além de passagens aéreas, pacotes de viagens, diárias de hotéis, locação de veículos e seguro viagem. Observa-se que elas têm um marketing agressivo visando transmitir a ideia de que "sempre" terão os melhores preços. As duas maiores OTAs do mundo valem na bolsa de Nova York mais de que as cinco principais redes hoteleiras juntas e são concorrentes diretas das agências, operadora (empresas que fornecem pacotes turísticos) e consolidadores (empresas que são atacadistas em passagens aéreas, intermediando a venda através das médias e pequenas agências), o que pode ocasionar na cadeia do turismo um grande risco aos envolvidos (VIEIRA, 2017a).

De acordo com o relatório $\mathrm{Smash}^{4}$, a CVC (operadora de turismo que atende agências de viagens e consumidor final) corresponde a mais de 50\% desse relatório. A Decolar.com, outra agência online, está em primeiro lugar em vendas entre as OTAs. Mesmo somando as vendas

\footnotetext{
${ }^{4}$ Informa as vendas de bilhetes aéreos internacionais das companhias estrangeiras no Brasil, com exceção da British e da Iberia.
} 
das três maiores OTAs que atuam no Brasil, a Decolar.com ainda fica em torno de $45 \%$ de vendas acima dos demais (ANDRADE, 2017). Segundo o autor, uma nova plataforma de vendas online está surgindo no mercado de viagens, na qual todas as pessoas que confirmarem reservas, terão uma comissão de 10\%, ou seja, todos poderão ser uma espécie de agente de viagem.

Registra-se, ainda, que em 2018 a OTA “Almundo" pertencente ao grupo Iberostar, que lidera o mercado argentino, vai iniciar suas operações no Brasil, esperando para 2019, um faturamento de $\mathrm{R} \$ 500$ milhões, confirmando um cenário positivo para o comércio online, não só por aqui, mas por toda a América Latina nos próximos anos (VIEIRA, 2017a).

Com o aumento da procura pelos passageiros das viagens pela internet, questiona-se sobre o futuro dos agentes de viagens. Mesmo com toda a tecnologia existente, para Cordeiro (2016), muitas pessoas continuam preferindo ter contato direto com os agentes de viagens. A especialização do profissional do turismo e sua consultoria serão fatores decisivos na sobrevivência desses profissionais. Mesmo que a internet possa mostrar muitas informações, a experiência vivida e transmitida pelo agente de viagens ainda fará a diferença nas decisões de muitos clientes.

\subsection{Estratégias e alternativas para gerar valor nos serviços tradicionais de agências de viagens}

A disputa pelo cliente de bilhetes aéreos tem algumas formas de se concretizar: a compra através das OTAs; a compra pelos sites; lojas e telemarketing das companhias aéreas e através das agências de viagens físicas. Observa-se que as OTAs, têm investido alto em marketing com o objetivo de trazer o cliente para comprar através de seus portais. As agências físicas utilizam também dos recursos da internet para comercializar seus produtos, com o diferencial do atendimento presencial. Ocorre que as OTAs têm ganhado espaço no mercado de viagens com o marketing de "preço baixo", o que nem sempre é uma realidade, pois existem acordos e ferramentas que permitem ao agente de viagens físico conseguir produtos com preços mais acessíveis do que nas OTAs. A taxa de serviço cobrada pelas agências físicas gira em torno de $R \$ 40,00$ até $10 \%$ do valor dos serviços, taxa essa, que OTAs também cobram, mas informam de uma forma diferente. Uma outra alternativa para o cliente seria adquirir seu bilhete aéreo diretamente dos sites das companhias aéreas, o que, nesse caso, geralmente, fica mais barato.

Os agentes físicos possuem várias facilidades, como: atendimento diferenciado, suporte em eventual problema; informações específicas de cada venda (que se efetuadas pelas OTAs podem ficar confusas), pesquisar pelo cliente as melhores opções, e em alguns casos ter preços mais atraentes do que as OTAs, dentre outros diferenciais. Já com as OTAs, os riscos são grandes quando efetuadas essas compras, pois muitos clientes não sabem onde ficam localizados esses estabelecimentos, ou como fazer em caso de problemas, cancelamentos, alterações e reclamações (VIEIRA, 2013).

A matéria divulgada pela Travel and Tour World (2017), ressalta que, embora tenha uma grande expansão das OTAs, a consultoria dos profissionais de viagens "físicos" continua prevalecendo. O texto enfatiza as vantagens de se comprar produtos de turismo com os agentes de viagens tradicionais, e não através das OTAs, pois o processo de viagem possui particularidades, que, dependendo do caso, se não conhecidas, podem ter impactos negativos para o cliente (HENRIQUE; MIRANDA, s.d.).

Empresários do setor de agências têm buscado formas de ingressar no comércio eletrônico. De acordo com a empresa americana de consultoria PhocusWright, o comércio de viagens 
de lazer no país corresponde a $10 \%$. O texto orienta que as empresas de viagem precisam se posicionar no mercado e esclarece, exemplificando, que o foco das OTAs é o preço, enquanto que nas agências tradicionais, os clientes estão preocupados com a segurança, comodidade, economia de tempo e facilidades para alteração de sua viagem (BORGES, 2012). Ainda para Borges (2012), há espaço para que as agências tradicionais ofereçam serviços online para seus clientes. Independentemente do tipo de negócio do turismo a ser trabalhado, a presença no mundo virtual é de extrema importância para a sobrevivência dos negócios.

O estudo "Análise Geral da Competitividade do Setor de Agenciamento de Viagens Brasileiro" (SEBRAE, 2011), mostra que uma das sete dimensões de análise da Matriz de Competitividade para o setor de agências de viagens é a tecnologia da informação como ferramenta importante a ser considerada pelo gestor.

Com a expansão do comércio online no Brasil, é possível observar que, desde 2012, esse comércio cresceu uma média de 4 pontos percentuais acima do mercado total. Observa-se que o produto aéreo tem predominância, tanto no comércio virtual, como no comércio tradicional, e que setores específicos do turismo, como o corporativo, ainda tem sua procura maior pelas agências tradicionais.

De qualquer forma, com o crescimento das OTAs, percebe-se que as agências físicas precisarão acompanhar as inovações, e as associações entre as agências físicas e as virtuais serão de extrema importância para agregar valor ao produto e melhorar as vendas. Segundo Oliveira (2015), as agências físicas não deixarão de existir, pois, para situações mais complexas, é importante a segurança e confiança de um agente de viagens físico.

Outro aspecto que ainda é uma oportunidade a ser mais bem explorada pelas agências físicas que buscam diferenciação é a segmentação de mercado, a qual consiste em dividir a oferta e a demanda em função de grupos homogêneos de clientes, como por exemplo: turismo de sol e praia; ecoturismo e negócios; terceira idade; jovens; por classe social; por motivação etc. A agência que utiliza dessa estratégia, consegue se especializar em um determinado segmento, podendo oferecer um produto diferenciado e exclusivo, pois a interação com o cliente é maior (ROLIM; ROLIM, 2016).

Dentro desse assunto de segmentação, o Ministério do Turismo (BRASIL, 2011) definiu alguns segmentos como prioritários. São eles: Turismo cultural; Pesca; Turismo de negócios; Ecoturismo; Turismo de sol e praia; Turismo de aventura; Turismo de estudos e intercâmbio e Turismo rural. A necessidade hoje é que a agência de viagens identifique qual o perfil de seus clientes, para que possa direcionar sua segmentação de forma acertada, lembrando que as mudanças são dinâmicas e as empresas precisam se adaptar (ROLIM; ROLIM, 2016).

\section{METODOLOGIA}

Para alcançar os objetivos propostos, os procedimentos de pesquisa envolveram estudos teóricos realizados em livros e material online, tais como artigos e sites especializados na temática da pesquisa e, ainda, sites ou revistas na área.

Além da revisão teórica, a metodologia compreendeu pesquisa de campo. O objeto de pesquisa foram os gestores das agências de viagens físicas do mercado de Campo Grande, em Mato Grosso do Sul. O número de agências de turismo ativas no município foi elencado a partir do CADASTUR (Cadastro de pessoas físicas e jurídicas que atuam no setor de turismo). Dentre o total de agências cadastradas em Campo Grande, as quais possuem a atividade de reserva e 
venda de passagens, totalizaram-se 146 estabelecimentos. Utilizou-se o desenho da amostragem não probabilística por conveniência, em que foram selecionadas 30 agências ativas e destas as 15 mais antigas (que operam antes de 1990) e as 15 mais novas (que operam após o ano de 2000). Essa amostra é válida pelo fato de estar composta por indivíduos que atendem aos critérios de entrada e que são de fácil acesso ao investigador, representando o público alvo objeto da pesquisa. O período selecionado, anterior a 1990 e posterior ao ano 2000, justifica-se, uma vez que a democratização do uso da internet no comércio eletrônico de passagens aéreas deu-se a partir da década de 90, o que para responder à pergunta de pesquisa, era essencial analisar as estratégias adotadas pelas empresas mais antigas para se manter no mercado e comparar o comportamento dessas diferentes empresas.

O CADASTUR foi a base de cadastro para a seleção das agências, mas, para definir as que existiam na década de 90, e após esse período, foi feito um levantamento do CNPJ (Cadastro Nacional de Pessoas Jurídicas) de cada agência, respeitando o ano de fundação, verificando se todas estavam em atividade atualmente. Um mesmo roteiro de perguntas foi aplicado para esses dois grupos de agências. As perguntas foram aplicadas no mês de outubro de 2017, para algumas agências de forma online e outras de forma impressa.

Após o dimensionamento do plano de amostragem, estabeleceu-se o instrumento de coleta de dados. Utilizou-se um roteiro semiestruturado para acompanhar e orientar as entrevistas com os gestores das empresas pesquisadas. Esse roteiro contemplou questões relativas à: caracterização das agências (nome da agência; ano de fundação; endereço; responsável legal; CNPJ; CADASTUR; segmento de atuação e volume médio mensal de bilhetes aéreos em 2016); caracterização do perfil de clientes (sexo; motivação da viagem; faixa etária; escolaridade; renda mensal; compras através da internet; meio de transporte mais utilizado na agência; possíveis mudanças no perfil dos clientes desde abertura da agência até a atualidade); e, no terceiro bloco, abordou-se a relação das agências tradicionais de Campo Grande com o comércio virtual de bilhetes aéreos com base na opinião dos gestores sobre a compra através da internet sem passar pela agência de viagens físicas; se o gestor acredita que o comércio virtual de bilhetes aéreos tem tirado o movimento de cliente das agências físicas; vendas de bilhetes antes da propagação da internet; a opinião do gestor sobre o futuro das agências físicas; sugestão do gestor das agências físicas para enfrentar o comércio virtual de bilhetes aéreos e quais pontos negativos e positivos em relação a este comércio. Por fim, perguntas sobre a quantidade média de bilhetes aéreos antes e depois da expansão da internet, sobre rentabilidade da agência e, ainda, o motivo pelo qual os clientes devem procurar suas agências e não as agências virtuais para comprar bilhetes aéreos.

Para auxiliar na análise do impacto das Online Travel Agencies (OTAs) no comércio tradicional das agências de viagens, foi utilizado o programa Planilha Empresarial Luz SWOT 3.5, o qual permitiu analisar a empresa e identificar dificuldades, pontos positivos, oportunidades e ameaças.

\section{RESULTADOS E DISCUSSÃO}

A pesquisa de campo compreendeu a investigação de 30 agências de viagens da Cidade de Campo Grande, no estado de Mato Grosso do Sul. O primeiro aspecto avaliado foi a caracterização das empresas. Das trinta empresas investigadas, tem-se grande variedade, tanto em função da idade das empresas, cujo ano de fundação variou de 1987 até 2016, quanto com relação ao 
montante de bilhetes aéreos vendidos por mês. No ano de 2016 esse quantitativo variou de $\mathrm{R} \$ 8.000$ a $\mathrm{R} \$ 900.000$ por mês entre as agências.

Observou-se, também, que, além desta heterogeneidade, as agências que continuam em atividade desde a década de 90 , são poucas, comparadas àquelas cadastradas no CADASTUR. Entende-se que o motivo principal na diminuição das agências de viagens físicas que operam desde a década de 90, é a mudança de comportamento dos clientes, influenciado pela evolução da tecnologia da informação, aquelas que permaneceram, precisaram se adequar à nova realidade e continuar a ter flexibilidade para se manter no mercado. Ricelly et al. (2017) apontam que as empresas podem se beneficiar desse cenário, uma vez que têm acesso aos mesmos conteúdos que os clientes e, de toda forma, mais conhecimento estimulará o surgimento de empresas e negócios inovadores, que deverão se basear em novos modelos de gestão.

Para escolher uma viagem há quinze anos, o cliente precisava primeiro escolher para onde era seu destino e ir até uma agência para levantar os custos. Hoje com a tecnologia tudo é diferente, como $90 \%$ de compras de qualquer segmento começa com uma consulta na internet, o cliente acaba se tornando uma vitrine (SILVA, 2017). O autor ainda enfatiza que até o 2018, aproximadamente, 2,6 bilhões de pessoas estarão conectadas na internet por smartphones. 0 turista chamado digital é conectado em mais de um canal, tendo como principal equipamento o telefone móvel com acesso à internet, sendo assim, as empresas precisam ser ecossistemas que compartilhem junto com o cliente deste universo, permitindo, até, a construção conjunta de produtos (CANDAU DEL CID, 2018).

Quanto à caracterização do perfil dos clientes, nas agências analisadas, verificou-se que, naquelas do primeiro grupo, ou seja, nas que surgiram antes ou durante a década de $90,70 \%$ afirmaram que seu público é feminino, já no segundo grupo (as que surgiram após a década de 90), tem-se mais heterogeneidade, $40 \%$ afirmaram que seu público é, em sua maioria, masculino, 26\% afirmaram que o público é, em sua maioria, feminino e 34\% afirmaram haver equilíbrio entre clientes homens e mulheres. Em matéria divulgada pelo Panrotas, uma pesquisa do Decolar.com, esclarece que $54 \%$ dos seus usuários são homens e $46 \%$ mulheres, que os homens alugam 2,5 vezes mais carros e as mulheres fazem compras $10 \%$ mais caras, entre outros itens citados, os homens usam mais os filtros de pesquisa, já as mulheres dão ênfase em diferenciais e conforto (MARTINS, 2017).

Sobre a motivação da viagem, os dois segmentos mais citados pelos entrevistados foram o lazer e os negócios. No primeiro grupo de agências, o lazer foi o motivo preponderante, citado em mais de $93 \%$ dos formulários como primeiro motivo. O segundo lugar ficou para motivação "negócios", citado por quase $47 \%$ dos entrevistados deste grupo. No segundo grupo de agências, novamente verificou-se mais heterogeneidade. Embora o motivo lazer ainda prepondere $(86,7 \%)$, houve aumento na motivação negócios $(66,7 \%)$ e acrescentam-se outras duas motivações: religiosa (13\%) e estudos (20\%). Conclui-se que tanto nas agências mais antigas, quanto nas mais jovens, não há divergências quanto às principais motivações. De toda forma, Bazanini et al. (2016, p. 55) afirmam, por meio de suas pesquisas que, "A segmentação aumenta o share da empresa, propiciando confiança aos gestores e aos clientes", o que é natural, uma vez que o conceito de segmentar o mercado é especializar-se num grupo de consumidores de gostos e comportamentos homogêneos, permitindo que a empresa ofereça exatamente o que o cliente deseja (ANSARAH, 2002).

Quanto à faixa etária, percebe-se grande variação do primeiro grupo de agências para o segundo. Nas agências mais antigas, a faixa etária de 36 a 45 anos foi preponderante, citada 
por 53\% dos entrevistados; essa mesma faixa etária, nas agências mais jovens, foi citada por 93\% dos entrevistados. Em segundo lugar, em ambos os grupos de agências, tem-se os públicos jovem (de 26 a 35 anos), que foi citado por 27\% das agências do primeiro grupo e por 33\% do segundo grupo, e o público maduro (56 a 65 anos), citado por $27 \%$ das agências do primeiro grupo e por $40 \%$ das agências do segundo grupo. A conclusão que se chega quanto à idade do público consumidor é de que, nas agências jovens, há uma grande incidência (93\%) de clientes jovens-maduros, ou seja, entre trinta e cinco e quarenta e cinco anos. Sobre a escolaridade, tem-se que, nas agências mais antigas, $67 \%$ dos clientes têm ensino superior completo, enquanto que, nas agências mais jovens, esse percentual sobe para $80 \%$. No aspecto renda, observou-se que houve diminuição do primeiro grupo para o segundo, a maior queda foi na faixa de renda que compreende os valores de 4,686 reais até 6,559 reais chegando a 13,3\%. Esse dado permite concluir que o público consumidor das agências mais antigas tem maior poder aquisitivo, embora tenha havido queda nesse padrão.

Com relação às compras pela internet, o grupo de entrevistados referente às agências mais antigas afirmou que $80 \%$ dos seus clientes efetuam compras pela internet, enquanto que, no segundo grupo de agências, esse percentual sobe para 100\%. Segundo Souza (2017), a utilização da internet para compras tem sido um hábito do brasileiro. A autora informa que, num estudo feito pelo Serviço de Proteção ao Crédito (SPC Brasil) e pela Confederação Nacional de Dirigentes Logistas (CNDL) em 27 capitais do nosso país, 89\% dos internautas compraram pelo menos um produto nos últimos 12 meses anteriores à pesquisa, em todas as classes sociais pesquisadas esse índice mantém-se elevado. Observa-se que, mesmo com a crise, 43\% dos consumidores online aumentaram a quantidade de produtos adquiridos em relação ao ano de 2016, e o principal ponto de destaque para o consumidor ser atraído para a compra online é a percepção de preço mais barato do que nas lojas físicas, e para aqueles produtos de fácil comparação. Quanto ao meio de transporte mais utilizado nas viagens, tem-se o avião 100\%, e 93\% no primeiro e segundo grupo respectivamente.

Um último questionamento nessa caracterização do perfil dos clientes foi em relação a se houve ou não alteração do perfil de clientes desde a abertura até os dias atuais. As respostas apontam que houve sim, mudança para $70 \%$ das agências entrevistadas.

De forma resumida, tem-se que o público das agências entrevistadas ficou mais heterogêneo, os segmentos predominantes nas agências ainda são lazer e negócios, contudo surgem viagens relacionadas aos motivos religião e estudos. O aumento do consumo na faixa etária de 26 a 35 anos deixa evidente uma outra característica das compras virtuais, a dos clientes millennials. Segundo Vianna (2015) , os millennials são considerados uma geração mais nova, conectada ao mundo virtual, que tem impactado os hábitos tradicionais do turismo, pois eles trazem um novo conceito, em que cada viagem é um momento único de experiência de vida, sempre bem informados pelos canais de comunicação através da internet, encaram as viagens como um estilo de vida, gostam de elaborar sua própria viagem, não necessitam pagar caro e utilizam de compartilhamento em suas viagens. De acordo com novos estudos de marketing (KOTLER; KARTAJAYA; SETIAWAN, 2017), os jovens consumidores serão maioria daqui para frente, a partir do envelhecimento da população atual. Ou seja, os nativos digitais ou geração Y serão em breve a maioria dos consumidores, e estes focam seu consumo em serviços e produtos que estejam relacionados com autorrealização e autoestima (WONG et al., 2017). Aqui se tem uma pista de para onde as agências de viagem devem focar, no que se refere aos consumidores do século XXI. 
$\mathrm{Na}$ análise das faixas de rendas, tem-se que houve uma diminuição do poder de compra dos clientes das agências do segundo grupo, com queda mais acentuada para aqueles que podem ser considerados como classe média (VILLAS BÔAS, 2017).

Por fim, verifica-se, claramente, que a internet interfere no processo de compra dos clientes de ambos os grupos de agências.

No bloco sobre a relação das agências tradicionais de Campo Grande com o comércio virtual de bilhetes aéreos, identificou-se que $42 \%$ das agências acham prejudicial a compra de bilhetes aéreos feita pelos clientes diretamente na internet, uma vez que não há suporte e informação nesse tipo de compra. Contudo, $14 \%$ dos entrevistados entendem que devem se aliar a internet e inovar. Não menos importante, $10 \%$ dos entrevistados, acreditam que a internet representa o futuro, e esse mesmo percentual que ela é uma concorrência desleal. Essa concorrência desleal, é um problema para os agentes que a elencaram, pois, considerando todo o custo que uma agência de viagens física tem, seja com aluguel, luz, água, telefonia, internet, tributos, funcionários, material administrativo, contador etc, sua abrangência é bem restrita em relação a uma OTA, que possui uma estrutura relativamente "pequena" para o tamanho do campo de atuação que ela tem à disposição, não deixando de citar o poder de negociação com os fornecedores, já que o movimento de uma OTA, é bem maior do que uma agência que atua no mercado de Campo Grande, MS.

Quando perguntados se houve redução do movimento das agências físicas em função das compras pela internet, $93 \%$ responderam que sim, e $40 \%$ dos gestores afirmaram que o volume de vendas era maior antes do advento da internet. Sobre o futuro das agências físicas, 38\% responderam que as agências continuarão a existir desde que tenham aperfeiçoamento, segurança e atendimento diferenciado, $27 \%$ afirmaram que as agências diminuirão, e $27 \%$ acreditam que precisam utilizar a internet como aliada, segmentar e adaptar-se as mudanças.

Sobre o que sugerem para enfrentar a situação referente ao aumento das compras pela internet, 34\% responderam que o atendimento diferenciado é a solução, e outros $35 \%$ variaram entre capacitação, inovação, marketing e adaptar-se às mudanças. Já 3,46\% acreditam na consultoria, 6,86\% ficaram entre o atendimento e utilizar a internet como aliada, 10,30\% utilizariam o know-how e o relacionamento com os clientes para enfrentar esta situação, 3,46\% preferem mudar de ramo, outros 3,46\%, consideram indiferente, e finalmente $3,46 \%$ veem condições iguais de negociação. Para Celdrán-Bernabeu, Mazón e Giner Sánchez (2018, p. 56), "Las empresas que apuesten por el uso de open data incorporarán un carácter innovador a sus productos y servicios que las hará diferenciarse de la competência". O mesmo assinalam Buhalis e Foerste (2014) e Longhi, Titz e Viallis (2014), ou seja, não parece ter muito espaço de negociação para aquelas empresas que não se alinharem com aspectos como internet das coisas, consulta e alimentação de dados abertos (open date). Kotler, Kartajaya e Setiawan (2017) abordam essas mudanças tecnológicas e seus impactos na forma de fazer marketing das empresas do século $X X I$, defendendo que, mesmo num momento de hieperconectividade, o cliente precisa da interação off-line, porque, apesar de informado, este excesso de informação deixa ele distraído e sem saber direito para onde ir.

No item referente aos aspectos positivos e negativos da venda virtual de bilhetes, destacam-se como pontos positivos: o atendimento em qualquer mercado e horário, os passageiros são mais informados e a compra é mais ágil e fácil. Quanto aos negativos: a informação não é completa, não há suporte para atender o cliente e a concorrência é desleal. 
Sobre o aumento ou diminuição da quantidade de bilhetes vendidos em comparação com o período anterior à propagação da internet, 43\% afirmam que diminuiu com a expansão da internet e $37 \%$ não são daquela época.

Uma outra questão foi se a rentabilidade da agência mudou desde a abertura até hoje, $50 \%$ responderam que hoje a rentabilidade é menor, 33\% que é maior, e $17 \%$ que continua a mesma. Divididos da seguinte forma: no primeiro grupo, agências da década de 90, 23,5\% afirmaram que a rentabilidade diminuiu, contra $26,5 \%$ do segundo grupo (agências após a década de 90), sobre as que responderam que a rentabilidade aumentou ficou dividido no mesmo percentual para os dois grupos de $16,5 \%$ (cada) e os que falaram que não mudou a rentabilidade foram no primeiro grupo $10 \%$ e no segundo grupo $7 \%$. Percebe-se que para um grupo de $10 \%$ das agências antigas, o advento da internet não abalou a rentabilidade, certamente possuem carteira de clientes bem fidelizada. Contudo elas não estão numa situação confortável, pois até mesmo as estratégias atuais de fidelização dos clientes incluem as redes sociais. Para Wichels (2018, p. 88), "As redes sociais, poderosas plataformas de relacionamento, captação e fidelização de clientes, nomeadamente o TripAdvisor, o Facebook e o Instagram ou a Blogosfera, estão a influenciar novos comportamentos do consumidor, obrigando a novas práticas em comunicação turística".

Quando perguntados sobre quais as vantagens de se comprar em agências físicas e não no comércio virtual de bilhetes, as respostas foram as seguintes: $46 \%$ responderam que o suporte e a confiabilidade oferecidos pelo agente seriam o motivo determinante, $40 \%$ apostam no atendimento diferenciado e na praticidade para o cliente, enquanto $10 \%$ acredita no suporte e melhores ofertas e $4 \%$ consideram indiferente.

Essa relação entre as agências físicas e o comércio virtual de bilhetes não é paritária, uma vez que a agência física não tem acesso ao conjunto total de informações necessárias. A maioria dos entrevistados compreendem que necessitam da internet como ferramenta essencial e, sem ela, não é possível manter-se no mercado. O fato de que as compras de bilhetes aéreos via comércio virtual tem aumentado é real, mas os gestores elencaram o atendimento diferenciado, o marketing, a capacitação, a inovação e a sensibilidade às mudanças, como ferramentas para enfrentar esta situação. Observou-se também que nenhuma das agências escolhidas vende só passagens aéreas, quer seja da década de 90, ou depois da década 90, o que evidencia, uma diversidade nos produtos das agências para a sua sobrevivência. Uma outra questão que merece destaque é que metade dos entrevistados afirmaram que a rentabilidade hoje é menor, demonstrando que houve um impacto negativo na receita das agências físicas, as quais estão precisando buscar alternativas para melhorar sua lucratividade.

Embora seja evidente a influência do comércio virtual nas vendas das agências físicas em Campo Grande, MS, observa-se que os entrevistados, na sua maioria, já sabem o caminho a ser percorrido para enfrentar esta situação, para se diferenciarem do comércio virtual e manter, pelo menos em parte, seus clientes.

Diante dos resultados utilizou-se uma matriz SWOT, para auxiliar na análise dos dados coletados. A matriz é dividida em ambiente interno que compreende as forças e as fraquezas da empresa, nesse caso, a empresa se refere às agências de viagens físicas do mercado de Campo Grande e o ambiente externo, que engloba as oportunidades e as ameaças no âmbito político, econômico e tecnológico.

Quanto ao ambiente interno destacam-se como forças e fraquezas o que mostra o quadro 1: 
Quadro 1 - Matriz SWOT, ambiente interno das agências físicas de Campo Grande, forças e fraquezas

\begin{tabular}{|l|c|l|c|}
\hline $\mathbf{5}$ Forças $\mathbf{5 0 0}$ & $\mathbf{5 0 0}$ & $\mathbf{5}$ Fraquezas & $\mathbf{1 8 0}$ \\
\hline Suporte ao cliente & 100 & Falta de Recursos Financeiros & 50 \\
\hline Confiabilidade & 100 & Limitação do Campo de Atuação & 40 \\
\hline Atendimento Diferenciado & 100 & Falta de Atualização do Profissional & 40 \\
\hline Relacionamento Cliente & 100 & Falta de Investimento em TI & 40 \\
\hline Marketing & 100 & Custos da Agência & 10 \\
\hline
\end{tabular}

Fonte: Elaborado pelos autores.

Analisando as forças e fraquezas das agências físicas pesquisadas, destaca-se que a figura do profissional é de extrema importância, pois quase todas as forças estão ligadas diretamente a este fato, salientando que, mesmo com toda a tecnologia que se tem apresentado nos últimos anos e a informatização do comércio (inclusive o comércio de bilhetes aéreos), o profissional ainda tem algo que as novas tecnologias não conseguiram substituir, o relacionamento entre pessoas, o que é muito considerado no comércio de produtos e serviços. Em contrapartida, esse profissional, precisa levar em conta muitas outras variáveis para se manter no mercado, entre elas, a mais impactante é a falta de recursos financeiros, pois sem ele, fica mais difícil dar a devida atenção às fraquezas.

Quanto ao ambiente externo, apresenta-se o quadro 2, com destaque para as ameaças e as oportunidades:

Quadro 2 - Matriz SWOT, ambiente externo das agências físicas de Campo Grande, ameaças e oportunidades

\begin{tabular}{|l|c|l|c|}
\hline $\mathbf{5}$ Oportunidades & $\mathbf{2 2 8}$ & $\mathbf{5}$ Ameaças & $\mathbf{2 0 4}$ \\
\hline $\begin{array}{l}\text { Utilização pela agência dos recursos da } \\
\text { internet }\end{array}$ & 48 & $\begin{array}{l}\text { Aumento dos aplicativos que ajudam o } \\
\text { cliente a se organizar sozinho }\end{array}$ & 60 \\
\hline $\begin{array}{l}\text { Possibilidades de novos segmentos de } \\
\text { mercado }\end{array}$ & 48 & Concorrência (Cias aéreas e Otas) & 48 \\
\hline Economia estável & 48 & Marketing agressivo das OTAs & 48 \\
\hline $\begin{array}{l}\text { Divulgação pela mídia de destinos de } \\
\text { turismo }\end{array}$ & 48 & $\begin{array}{l}\text { Utilização da Internet para compras pelo } \\
\text { público geral }\end{array}$ & 48 \\
\hline $\begin{array}{l}\text { Possibilidades de parcerias com novos } \\
\text { fornecedores }\end{array}$ & 36 & & 0 \\
\hline
\end{tabular}

Fonte: Elaborado pelos autores.

Com relação ao ambiente externo, as agências físicas podem buscar ações que aproveitem as oportunidades postas pelo cenário atual, tais como explorar de forma correta o que a internet tem a oferecer, seja criando sites, participando de redes sociais, desenvolvendo aplicativos, buscando novos fornecedores e fortalecendo essas parcerias, segmentando, além de estar atento as divulgações que são feitas pela mídia de locais turísticos. Em contrapartida, é fundamental também estarem atentas para combaterem as ameaças destacadas no quadro 2, pois, como se pode observar, tem crescido o acesso ao comércio virtual em geral, em todos os segmentos, fato esse que gera impacto na venda de bilhetes aéreos das agências físicas e que leva o agente de viagens tradicional a se reinventar para manter-se no mercado. 
A figura 1 apresenta um resumo geral dos fatores internos e externos, deixando clara a atual situação do objeto pesquisado. Verifica-se que o cenário ainda é positivo para as agências físicas, uma vez que a pontuação das forças excede, bastante, à pontuação das fraquezas. 0 mesmo ocorre com as oportunidades em detrimento das ameaças, embora a distância entre ambas seja menos proeminente.

Figura 1 - Resumo geral dos fatores internos e externos

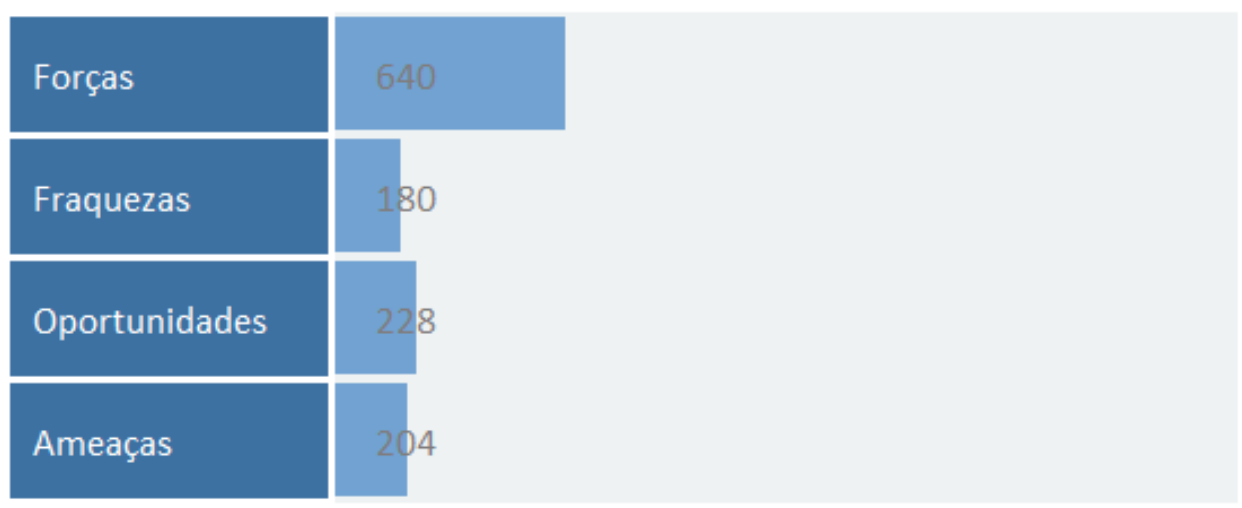

Fonte: Elaborado pelos autores.

A figura 2 corrobora com o quadro 3 e indica o índice de favorabilidade em que as agências físicas se encontram.

Figura 2 - Índice de favorabilidade das agências físicas em relação a aplicação da matriz SWOT

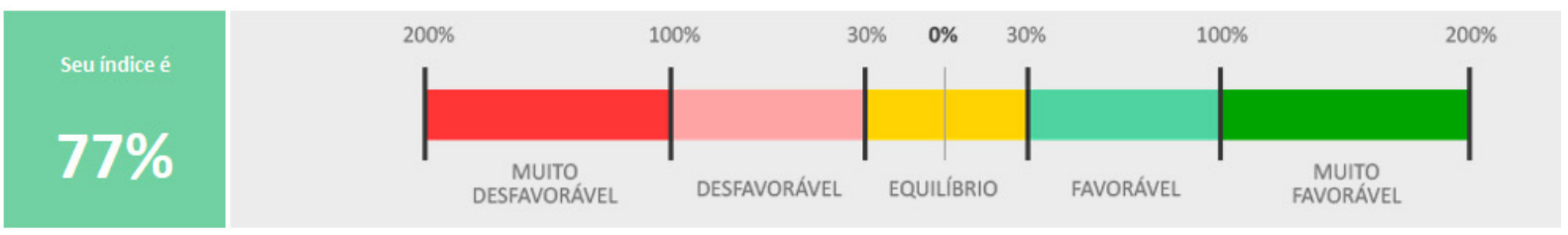

Fonte: Elaborado pelos autores.

De acordo com a análise feita por meio da matriz SWOT, as empresas físicas pesquisadas encontrar-se-iam num cenário ainda de equilíbrio, com tempo suficiente para se reposicionarem no atual cenário global de mudanças tecnológicas e sociais que se apresenta.

\section{CONSIDERAÇÕES FINAIS}

É fato que a internet trouxe uma nova perspectiva para as agências de viagens físicas, inclusive, criando possibilidades de novos negócios. As agências de viagens tradicionais continuarão tendo seu espaço, mas terão que investir em profissionais mais qualificados, na segmentação aliada ao atendimento personalizado, na praticidade para os consumidores, no suporte e no relacionamento com as pessoas. A agência do futuro não estará preocupada apenas com o preço, mas em agregar valor aos serviços de acordo com seu público alvo. Verificou-se que o movimento de bilhetes aéreos das agências de viagens físicas de Campo Grande, MS foi afetado de forma negativa pela expansão da internet. Outra questão que merece destacar é que o comércio virtual 
tende a crescer com o passar dos anos, influenciado pelas tecnologias associadas à internet, trazendo um novo reposicionamento para todo o mercado diretamente impactado por essas tecnologias.

Quanto ao cenário atual no que se refere ao uso da internet no comércio de produtos turísticos em geral, identificou-se total dependência das tecnologias associadas a internet, pois cada vez mais toda a cadeia do produto turístico busca formas de alcançar mais clientes e facilitar os procedimentos de comercialização. Ainda, caracterizou-se o perfil atual do consumidor de produtos turísticos a partir das empresas investigadas e identificou-se aspectos positivos e negativos na relação das agências tradicionais de Campo Grande com o comércio virtual de bilhetes aéreos. A análise realizada permite salientar que é preciso que as agências de viagens tradicionais utilizem, também, de todos os expedientes oferecidos pelos recursos tecnológicos disponíveis para seu benefício. Sabendo que a concorrência (seja física ou virtual) sempre vai existir e que mudanças podem ocorrer a qualquer momento, cabe a cada empresário estar preparado para as possíveis correções de rumo.

\section{REFERÊNCIAS}

ANDRADE, A. Decolar.com vende quase o dobro da CVC no internacional. Panrotas, 2017. Disponível em: http://www.panrotas.com.br/noticia-turismo/agencias-de-viagens/2017/08/decolarcom-vende-quase-odobro-da-cvc-no-internacional_149144.html. Acesso em: 29 ago. 2017.

ANSARAH, M. G. R. (Org.). Turismo- segmentação de mercado. São Paulo: Futura, 2002.

BORGES, M. P. OTAs: Ameaça ou Oportunidade? @gente no turismo-turismo digital, nov. 2012. Disponível em: http://agentenoturismo.com.br/2012/11/21/otas-ameaca-ou-oportunidade/. Acesso em: 8 set. 2017.

BAZANINI R.; FERREIRA, A.; FÉRIS, J. R. R; RAVAGNANI, F. A. A estratégia de segmentação de mercado comovantagem competitiva: um estudo exploratório no setor de turismo "single" a partir da cidade de São Paulo. PODIUM Sport, Leisure and Tourism Review, v. 5, n. 1, jan./abr. 2016.

BUHALIS, D.; FOERSTE, M. SoCoMo marketing for travel and tourism: empowering co-creation of value. Journal of Destination Marketing and Management, v. 4, n. 3, p. 151-61, 2014. doi: http://doi.org/10.1016/j. jdmm.2015.04.001

BRASIL. Ministério do Turismo. Ministério do Turismo publica manuais de segmentação turística. Brasília, jan. 2011. Disponível em: http://www.turismo.gov.br/ultimas-noticias/1845-ministerio-do-turismo-publicamanuais-de-segmentacao-turistica.html. Acesso em: 9 set. 2017.

BRITO, B. D. M. de. Tecnologia da Informação Turística. Rio de Janeiro: SESES, 2017.

CANDAU DEL CID, M. La Calidad colaborativa: um nuevo concepto para la calidad turística. Cuadernos de Turismo, n. 42, p. 47-70, 2018. doi: http://dx.doi.org/10.6018/turismo.42.02

CEDEÑO, K. Veja dicas para elevar as reservas diretas em seu hotel. Panrotas, ago. 2016. Disponível em: http://www.panrotas.com.br/noticia-turismo/hotelaria/2016/08/veja-dicas-para-elevar-as-reservasdiretas-em-seu-hotel_128117.html?leiaTambem. Acesso em: 3 dez. 2017.

CELDRÁN-BERNABEU, M. A.; MAZÓN, J.-N.; GINER SÁNCHEZ, D. Open Data y turismo. Impli-caciones para la gestión turística en ciudades y destinos turísticos inteligentes. Investigaciones Turísticas, n. 15, p. 49-78, 2018. doi: http://dx.doi.org/10.14198/INTURI2018.15.03. Acesso em: 6 abr. 2018. 
COOPER, C. et al. Turismo: princípios e prática. [Tourism: principlesandpractice]. Sandra Ferrapontoff Lemos (Sup.). Tradução de Roberto Cataldo Costa. 2. ed. Porto Alegre: Bookman, 2003.

CORDEIRO, F. Consultoria é a chave para sobrevida do agente de viagens. Panrotas, out. 2016. Disponível em: http://www.panrotas.com.br/agencia-do-futuro/agencias-de-viagens/2016/10/consultoria-e-a-chavepara-sobrevida-do-agente-de-viagens_141058.html. Acesso em: 8 set. 2017.

DIAS, Reinaldo. Introdução ao Turismo. São Paulo: Atlas, 2005.

FONSECA, S. As principais OTAs do Brasil. Envision Tecnologia, out. 2014. Disponível em: http:// envisiontecnologia.com.br/principais-otas-brasil/. Acesso em: 8 set. 2017.

HENRIQUE, L.; MIRANDA, M. Agências de viagens tradicionais x OTAs: confira vantagens. [S.d.]. Disponível em: http://www.pressclub.com.br/pk/noticia.asp?id=1534\&idn=16409\&fonte=ABAV\%20Nacional. Acesso em: 3 dez. 2017.

INFRAERO. Anuário Estatístico Operacional 2016, Brasília: INFRAERO, 2017. Disponível em: www.infraero. gov.br/images/stories/Estatistica/anuario/anuario_2016.pdf. Acesso em: 8 set. 2017.

INSTITUTO BRASILEIRO DE GEOGRAFIA E ESTATÍSTICA (IBGE). Campo Grande. Brasília, 2017. Disponível em: https://cidades.ibge.gov.br/brasil/ms/campo-grande/panorama. Acesso em: 6 mar. 2018.

KOTLER, P.; KARTAJAYA, H.; SETIAWAN, I. Marketing 4.0. Tradução de Ivo Korytowski. Rio de Janeiro: Sextante, 2017.

LONGHI, C.; TITZ, J.; VIALLIS, L. Open data: challenges and opportunities for the tourism industry. In: MARIANI, M. M.; BAGGIO, R.; BUHALIS, D.; LONGHI, C. (Ed.). Tourism Management, Marketing, and Development. New York, 2014. p. 57-76.

MARTINS, M. 5 diferenças de homens e mulheres em compras nas OTAs. Panrotas, jul. 2017. Disponível em: http://www.panrotas.com.br/noticia-turismo/mercado/2017/07/5-diferencas-de-homens-e-mulheresem-compras-nas-otas_147931.html. Acesso em: 17 jul. 2017.

MELLER-DA-SILVA, F.; MARCIANO, P. O. Modelo de Negócio inovador: a empresa Netflix. Revista Eletrônica Científica do CRA-PR, v. 4, n. 1, p. 1-19, 2017. Disponível em: http://www.spell.org.br/documentos/ ver/47944/modelo-de-negocio-inovador--a-empresa-netflix. Acesso em: 6 mar. 2018.

MONTEIRO, J. O.; MONTEIRO, J. O. Novas tendências no mercado turístico: análise de algumas agências de viagens online no Brasil. In: CONGRESSO NACIONAL DE EXCELÊNCIA EM GESTÃO, 10., 08 e 09 ago. 2014. Anais [...]. Rio de Janeiro: FIRJAN, 2014. Disponível em: www.inovarse.org/sites/default/files/T14_0306_0. pdf. Acesso em: 5 dez. 2017.

OLIVEIRA, P. Cresce procura por agências de turismo online. Portal do Ministério do Turismo, Brasília, out. 2015. Disponível em: http://www.turismo.gov.br/\%C3\%Baltimas-not\%C3\%Adcias/5587evolu\%C3\%A7\%C3\%A3o-tecnol\%C3\%B3gica-alavanca-entrada-de-ag\%C3\%Aancias-de-turismo-no-mundovirtual.html. Acesso em: 8 set. 2017.

OLIVEIRA, J. E. S.; RESENDE, M. G. As mudanças no turismo com o advento da tecnologia de informação. Revista de Iniciação Científica - Cairu, Salvador, n. 1, jun. 2014. Disponível em: www.cairu.br/riccairu/ pdf/artigos/10_MUDANCAS_TURISMO.pdf. Acesso em: 10 set. 2017.

OTTO, G. Maiores distribuidores de viagens - ranking anual 2016 Panrotas. Blog da Gabriela Otto, mar. 2016. Disponível em: http://gabrielaotto.com.br/blog/maiores-do-turismo/. Acesso em: 8 set. 2017. 
RICELLY PINTO DE FARIAS, T.; COSTA, J. H.; PERINOTTO, C.; RIANI, A. Empresas turísticas, redes sociales y negocios electrónicos: reflexiones a partir de la obra de Manuel Castells. Estudios y Perspectivas en Turismo, Buenos Aires, v. 26, n. 3, p. 626-43, 2017.

ROLIM, H.; ROLIM, M. Segmentação da oferta nas agências de viagem. Portal Sebrae, jun. 2016. Disponível em: http://www.sebrae.com.br/sites/PortalSebrae/artigos/segmentacao-da-oferta-nas-agencias-de-viag em,1336201221455510VgnVCM1000004c00210aRCRD. Acesso em: 8 set. 2017.

SEBRAE. Análise Geral da Competitividade do Setor de Agenciamento de Viagens Brasileiro. 2017.

SILVA, R. Disputa OTA X agente e 'era digital' são discutidas na Aviesp. Panrotas, nov. 2017. Disponível em: http://www.panrotas.com.br/noticia-turismo/eventos/2017/11/disputa-ota-x-agente-e--39era-digital-39sao-discutidas-na-aviesp_151530.html. Acesso em: 27 nov. 2017.

SOUZA, L. Pesquisa indica que $43 \%$ dos internautas fizeram mais compras online este ano. Agência Brasil, 21 jun. 2017. Disponível em: http://agenciabrasil.ebc.com.br/geral/noticia/2017-06/pesquisa-indica-que43-dos-internautas-compraram-online-este-ano . Acesso em: 6 jan. 2018.

VIANNA, A. Os Millennials já invadiram o seu negócio? Hotelier News, abr. 2015. Disponível em: http:// www.hoteliernews.com.br/artigos/alessandra-vianna-i-os-millennials-ja-invadiram-o-seu-negocio-i-66777. Acesso em: 10 dez. 2017.

VIEIRA, C. Setor de viagens: a batalha entre as agências de viagens físicas e as virtuais. Notícias e Negócios, abr. 2013. Disponível em: http://noticiasenegocios.com.br/2013/04/setor-de-viagens-a-batalha-entre-asagencias-de-viagens-fisicas-e-as-virtuais/. Acesso em: 8 set. 2017.

VIEIRA, R. Cartas na mesa. Anuário de Distribuição Panrotas. São Paulo, nov. 2017a, p.17-20.

VIEIRA, R. Tudo o que você precisa saber sobre o domínio das OTAs. Panrotas, jun. 2017b. Disponível em: http://www.panrotas.com.br/noticia-turismo/mercado/2017/06/tudo-o-que-voce-precisa-saber-sobreo-dominio-das-otas_146946.html?pesquisa. Acesso em: 8 set. 2017.

VILLAS BÔAS, B. Na retomada, renda da classe 'A' sobe 6 vezes mais depressa. Valor Econômico set. 2017. Disponível em: http://www.valor.com.br/Brasil/5115278/NA-Retomada-Renda-da-classe-sobe-6-vezesmais-depressa\# . Acesso em: 14 dez. 2017.

VINHOLES, T. Os aviões comerciais mais importantes da história. Airway, fev. 2017. Disponível em: https:// airway.uol.com.br/os-avioes-comerciais-mais-importantes-da-historia/. Acesso em: 19 nov. 2017.

WICHELS, S. Comunicação turística desafios e tendências na contemporaneidade. O caso de Tenerife. Dos Algarves: A Multidisciplinary e-Journal, n. 32, p. 88-106, 2018.

WONG, A. M.; RUIZ, E. R.; SILLER, J. F. M.; RAMIREZ, K. L.. Los valores en los consumidores millennials de la ciudad de Saltillo, Coahuila. European Scientific Journal October edition, v. 13, n. 28, p. 371-80, 2017.

\section{Sobre os autores:}

Rodrigo Adolfo Stefanes Zampieri - Especialista em Planejamento e Gestão Pública e Privada do Turismo pela Universidade Estadual de Mato Grosso do Sul (UEMS), Dourados. Graduado em Direito pelo Centro Universitário de Campo Grande-(UNAES).E-mail: rodrigozampieri@bol.com.br, Orcid: http://orcid.org/0000-0003-4392-9496 
Dores Cristina Grechi - Bacharel em Turismo e Hotelaria e Doutora em Economia do Desenvolvimento Regional. Professora/pesquisadora da Universidade Estadual de Mato Grosso do Sul (UEMS). Ministra aula nos cursos de graduação e pós-graduação em Turismo; no mestrado em Desenvolvimento Regional e Sistemas Produtivos. Líder do Grupo de Pesquisa Turismo: Planejamento, Gestão e Desenvolvimento/PLANGEDTur. E-mail: cgrechi@uol.com.br. Orcid: http://orcid.org/0000-0002-4481-0166 